\title{
Aplicação dos nanofiltros de carbono no tratamento de águas para remoção de contaminantes: uma visão geral
}

\section{Application of carbon nanofilters in water treatment for contaminant removal: an overview \\ Data de entrada: 04/05/2020 \\ Data de aprovação: 05/06/2020}

Yuri de Oliveira Lima ${ }^{1 *} \mid$ Givanildo Santos da Silva ${ }^{1}$

ORCID ID

Lima YO (D) https://orcid.org/0000-0002-0671-2151
DOI: https://doi.org/10.36659/dae.2021.072

Silva GS (D) https://orcid.org/0000-0002-4021-4666

\section{Resumo}

É explícito que, com o passar dos anos, tecnologias novas vão aparecendo, o que não é diferente para os meios de produção de água potável, mais especificamente para remoção de poluentes, dada sua grande importância para o ser humano. 0 crescimento exponencial das cidades e das indústrias é o principal causador da degradação das fontes de água, devido ao mau descarte de resíduos e à disposição final de esgotos irregulares, ocasionando a contaminação das fontes de água. Com os processos convencionais de tratamento de água é possível remover alguns desses contaminantes, porém alguns não são removidos da água, o que pode trazer infecções graves ao ser humano. Diante disso, os estudos com os nanofiltros de carbono vêm crescendo, apresentando um grande potencial para filtragem de contaminantes químicos e biológicos tóxicos à saúde. Suas excelentes propriedades estruturais, químicas e a manipulação da matéria em nível manométrico fazem os nanofiltros de carbono se destacarem em meio a outros materiais, podendo remover vírus, bactérias e metais pesados presentes na água. O presente artigo visa apresentar dados e informações que revelem a utilidade dos nanofiltros de carbono para tratamento de água, mostrando seu potencial para a filtragem e remoção de contaminantes presentes neste recurso que se tornou limitado.

Palavras-chave: Nanofiltros de carbono. Nanotubos de Carbono. Vírus. Bactérias. Metais.

\section{Abstract}

It is explicit that with the passing of the years new technologies are appearing, and it is not different for the means of production of potable water, more specifically for the removal of pollutants, given its great importance for the human being. The exponential growth of cities and industries are the main cause of the degradation of water sources, due to the bad disposal of waste and final disposal of irregular sewers, causing the contamination of the water sources. With conventional water treatment processes it is possible to remove some of these contaminants; however, some are not removed from the water, which can bring serious infections to the human being. Therefore, studies with carbon nanofilters have been increasing, presenting great potential for the filtration of chemical and biological contaminants toxic to health. Its excellent structural, chemical and nanometric properties make the carbon nanofilters stand out from other materials and can remove viruses, bacteria and

\footnotetext{
${ }^{1}$ Centro Universitário Tiradentes (Unit) - Maceió - Alagoas - Brasil.

* Autor correspondente: engyuri.olaoutlook.com.
} 
heavy metals from the water. The present paper aims to present data and information that reveal the usefulness of carbon nanofilters for water treatment, showing their potential for the filtration and removal of contaminants present in this resource that has become limited.

Keywords: Carbon nanofilters. Virus. Bacteria. Metals.

\section{INTRODUÇÃO}

A água é um dos recursos naturais e renováveis mais importantes para o ser humano, mas com o passar dos anos esse recurso vem sendo considerado bastante limitado. $O$ aumento da população de forma desordenada, a urbanização, o crescimento industrial e agrícola são fatores que influenciam diretamente na poluição e na deterioração das principais fontes de consumo de água potável, seja pela falta de controle, tratamento e disposição final de esgotos ou até mesmo a disposição inadequada dos resíduos sólidos.

Nas grandes cidades, as atividades industriais aparecem como uma das principais causadoras de contaminação ambiental; dentre elas estão a queima de carvão mineral e petróleo, que são utilizadas como fontes de energia nas indústrias. Essas e outras práticas promovem a liberação de diversas substâncias tóxicas para o meio ambiente (OGA, 2003 apud BASTOS, 2013).

Com tais fatores, o tratamento de água aparece como uma das principais opções para a reutilização desse recurso que se tornou limitado. Porém, a contaminação das águas por substâncias químicas e biológicas tóxicas e cada vez mais pesadas faz com que o tratamento de água realizado principalmente por processos convencionais, compreendendo coagulação, floculação, sedimentação, filtração e cloração, torne-se cada vez mais ineficazes na descontaminação das águas, o que requer a incorporação de novas tecnologias.

Os estudos em nível nanométrico aparecem como uma das principais soluções tecnológicas atualmente, podendo ser aplicados em diversas áreas, apresentando inúmeros resultados satisfatórios. Tal tecnologia se fundamenta no estudo e desenvolvimento de técnicas e de ferramentas adequadas para posicionar átomos e moléculas em locais previamente estabelecidos, de maneira a obter estruturas e materiais de interesse.

Diante disso, a nanotecnologia aparece como uma ótima alternativa para encontrar soluções para os problemas referentes ao tratamento de água, com técnicas mais avançadas de filtração com membranas como, microfiltração, ultrafiltração, nanofiltração e osmose reversa, mostrando desempenho superior ao tratamento e remoção de contaminantes químicos e biológicos em sistemas convencionais, porém seu uso ainda é limitado devido aos altos custos operacionais (PIANTA et al., 2000).

Dentro do contexto supracitado, alguns materiais se destacam devido a suas propriedades, como os nanotubos de carbono, que apresentam ótimas propriedades mecânicas, elétricas e térmicas, sobretudo devido a suas características estruturais e químicas. Com o poder de manipulação da matéria em nível nanométrico, os nanotubos de carbono podem se tornar um dos meIhores materiais para filtragem da água.

Mesmo sendo uma tecnologia ainda pouco estudada, dia após dia a nanotecnologia vem se tornando realidade no meio científico com materiais de propriedades excelentes e aplicações milimétricas, e seu uso pode trazer uma grande reformulação no estudo dos materiais. 


\section{TRATAMENTO DE ÁGUA POR NANOFILTROS DE CARBONO}

Os processos de tratamento para reutilização de águas são geralmente constituídos pelos processos de tratamento biológico, como coagulação, floculação, sedimentação, filtração, cloração e, em algumas situações, a adsorção de carvão ativado.

Segundo Upadhyayula et al. (2009), os processos de tratamento convencionais são construídos com base em alguns fatores importantes. O primeiro é o fato de que a água que entra na estação está contaminada apenas por contaminantes químicos e biológicos que ocorrem de maneira natural. 0 segundo fator aparece tipicamente em águas de nascentes contaminadas pelo escoamento de águas superficiais e principalmente pela descarga de esgotos não tratados. E o terceiro fator ronda em volta de um questionamento em que os contaminantes presentes na água seriam ou não removidos por completo pelo processo de tratamento convencional constituído pelas etapas de coagulação, floculação, filtração e desinfecção, visto que é um fator considerável e que pode colocar em risco a saúde da população.

Recentemente, a filtração por membranas no tratamento de água tem sido utilizada mundialmente para redução da concentração de partículas e materiais orgânicos naturais na água. Sobretudo, suas aplicações também apresentam uma grande capacidade para processos de remoção de microrganismos pato- gênicos, como protozoários, bactérias e vírus (MOSTAFAVIA et al., 2009).

Entre os processos de filtragem com membrana, a nanofiltração com a adsorção dos nanotubos de carbono é a mais recente tecnologia estudada, apresentando vantagens em relação aos processos convencionais de filtração, devido ao poder manipulação de matéria em nível atômico, especialmente para o tratamento de águas contaminadas com metais pesados, bactérias e vírus, que em geral são substâncias e microrganismos tóxicos e que geram doenças aos seres vivos.

Os Nanotubos de Carbono ou NTCs - CNT, do inglês carbonnanotube, são definidos como átomos de carbono arranjados em anéis aromáticos condensados formados por lençóis de grafeno enrolados em cilindros (IIJAMA, 1991), ou simplesmente são cilindros vazios por dentro que são formados por alótropos do carbono com proporções nanométricas (OLIVEIRA, 2017), podendo ser do tipo Nanotubo de Parede Simples - SWNTs, do inglês single-wallednanotubes, podendo ser também de Nanotubo de Parede Múltipla - MWNTs, do inglês multi-wallednanotubes, tendo um tipo especial de MWNT, que é o nanotubo de parede dupla - DWNT, do inglês double-wall carbono nanotubes, podendo ser observados ambos na Fig. 1. Os NTCs apresentam excelentes propriedades mecânicas para a tração e ainda melhores para a compressão, além de mostrar também ótimas propriedades térmicas e elétricas, além de excelentes características estruturais e químicas. 


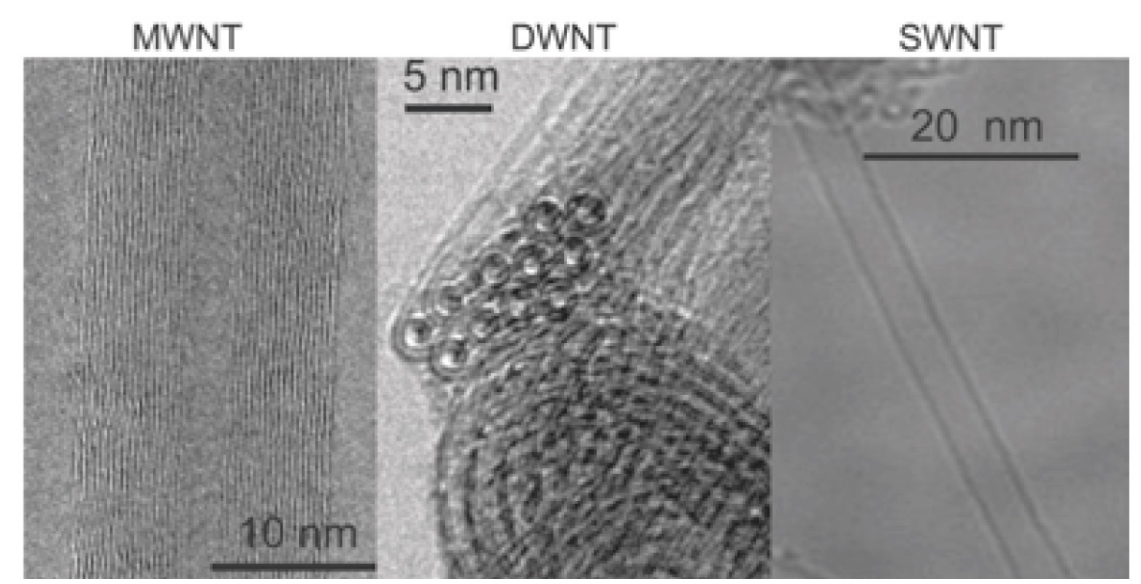

Figura 1 - Imagens de microscopia eletrônica de transmissão de nanotubos (SWNT) de parede simples, (MWNT) de paredes múltiplas, (DWNT) de parede dupla.

Fonte: Química Nova (2007).

Os nanofiltros de carbono consistem basicamente em um conjunto de nanotubos de carbono radicalmente orientados, embalados como um grupo de espaguetes e colados uns aos outros, formando uma membrana filtrante, capaz de reter substâncias indesejadas em nível molecular.

Em um contexto geral, a nanofiltração é o processo de separação por membranas, cuja técnica é capaz de separar soluções heterogêneas e solutos que se encontram dissolvidos na água. A membrana atua como uma barreira seletiva, ou seja, permite apenas a passagem de determinados componentes enquanto impede a passagem de outros. Essa técnica retém os sais bivalentes com 0,001 $\mu \mathrm{m}$ molecular e requer pressão de trabalho entre 10 a 25 bar (CHEIS, 2013 apud NÓBREGA 2016).

\subsection{Remoção de contaminantes biológicos}

A remoção de vírus e bactérias é extremamente importante na produção de água potável e está sujeita a muitas discussões. A remoção dos protozoários Giardia e Cryptosporidium de fontes de água superficiais é uma prioridade principal para muitos governos e empresas de água potável (BRUGGEN et al., 2002).

Os métodos de tratamento de água convencionais tornaram-se cada vez mais complexos devido às consequências da industrialização e urbanização, que resultaram na liberação de inúmeras substâncias químicas tóxicas de origem antropogênica em corpos d'água, como metais pesados, compostos orgânicos persistentes e desreguladores endócrinos. A liberação de toxinas devido à presença de determinadas populações bacterianas é outro fator que dificulta o processo de tratamento convencional, pois influencia diretamente na qualidade geral da água. Por exemplo, as cianobactérias são as principais responsáveis pela liberação da microcistinas, que são toxinas altamente prejudiciais à saúde e ao meio ambiente (UPADHYAYULA et al., 2009).

A força única dos NTCs na adsorção de contaminantes biológicos é principalmente devida ao pequeno tamanho dos poros, tendo um grande potencial para remoção de microrganismos presentes no sistema de distribuição de água. Durante o processo de filtragem, as moléculas de água podem sair por buracos nanométricos 
das paredes dos nanotubos; já as bactérias e os vírus ficam entupidos. Uma característica importante a ser relatada é a grande resistência dos nanotubos ao calor e a esforços mecânicos, podendo ser limpados repetitivamente com autoclaves ou dispositivos de ultrassom (SEGOVI, 2010). Além disso, a citotoxidade microbiana dos NTCs tem uma pequena influência na concentração de bactérias.

A adsorção bacteriana nos nanotubos de carbono tem três características únicas. Em primeiro lugar, a capacidade de adsorção microbiana dos NTCs relatadas até agora é mais alta do que em qualquer outro meio adsorvente comercialmente disponível. Em segundo lugar, os NTCs expressam adsorção seletiva de bactérias, uma característica que não é geralmente vista em outros adsorventes. Finalmente, a cinética de adsorção de bactérias nos nanotubos é quase instantânea, sugerindo seu uso em aplicações como sensores de patógenos, onde é desejado concentrar rapidamente o contaminante alvo.

Segundo Upadhyayula et al. (2009), os nanotubos de carbono apresentam características antimicrobianas, o que leva ao combate de uma gama de microrganismos, como Micrococcus luteus, Streptococcus mutans, Escherichia coli, Salmonella, além de algumas espécies de protozoários e vírus, como Tetrahymena e Bacteriófago, respectivamente. Na Fig. 2 podem ser vistas as bactérias do tipo $\mathrm{E}$. coli expostas aos nanotubos de carbono de parede múltipla e parede simples.
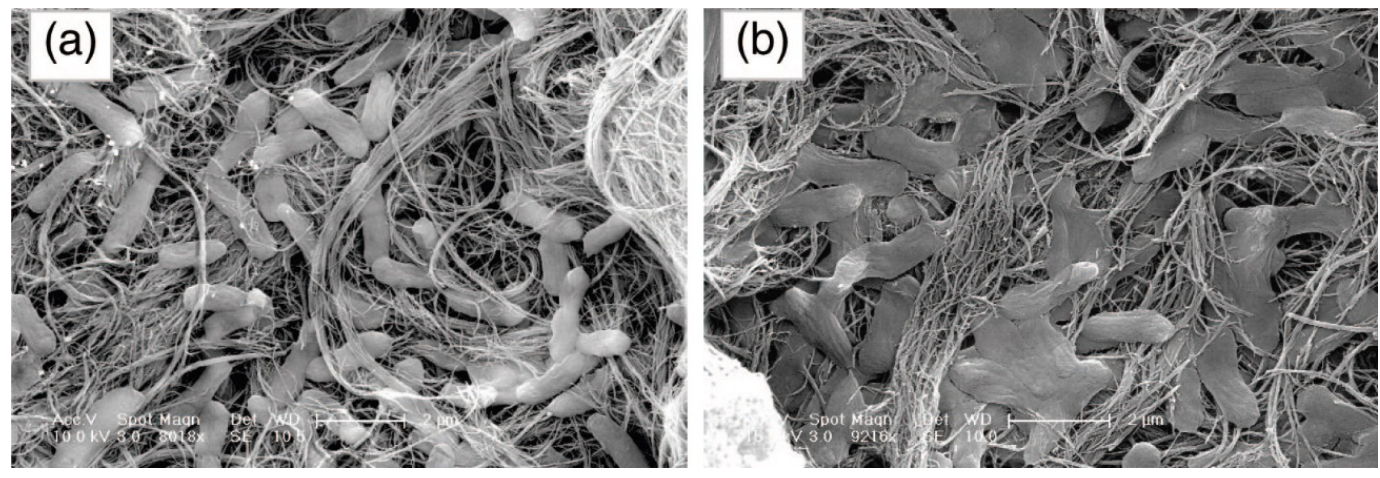

Figura 2 - Imagens de microscopia eletrônica de varredura (SEM) de células de E. coli expostas a CNTs. (a) Células incubadas com MWNTs por 60 min. (b) Células incubadas com SWNTs por $60 \mathrm{~min}$. Fonte: KANG et al (2008).

Mostafavi (2009) relata a eficiência dos nanofiltros de carbono sobre diferentes pressões, ou seja, quando os nanofiltros são submetidos ao aumento da pressão, a velocidade do fluxo de água aumenta através dos mesmos, mas a velocidade de transferência de massa do vírus é baixa e, portanto, a velocidade de transferência de massa é diferente, fazendo com que a concentração do vírus diminua com o aumento da pressão. Isso mostra que os nanofiltros de carbono apresentam uma boa permeabilidade da água, fluxo de filtragem e podem ser utilizados para a remoção de vírus com alta eficiência.

Segundo Bruggen (2002), Microfiltração (MF) e ultrafiltração (UF) podem ser usadas para desinfecção. $O$ tamanho de um vírus varia entre 20 e $80 \mathrm{~nm}$, enquanto as membranas de UF têm poros de aproximadamente $10 \mathrm{~nm}$ e mais, de modo que a remoção completa é teoricamente possível. Bactérias $(0,5$ a $10 \mathrm{~mm})$ e cistos e oocistos de protozoários ( 3 a $15 \mathrm{~mm}$ ) são maiores, e sua remoção pode ser garantida utili- 
zando membranas de UF. Porém existem vírus menores que exigem membranas ainda mais eficientes. Sendo assim, os nanofiltros de carbono que possuem tamanhos de poros abaixo de $1 \mathrm{~nm}$ se mostram ainda mais eficientes que outras membranas.

\subsection{Remoção de metais pesados}

Grande parte dos metais pesados encontrados na água geralmente são resultados de atividades antropogênicas, como mineração, atividades metalúrgicas, descargas inadequadas de esgoto, lixos, uso de combustíveis. Elementos como Co (Cobalto), Cu (Cobre), Fe (Ferro), Hg (Mercúrio), $\mathrm{Cr}$ (Crômo), Ni (Níquel), Cd (Cádmio), Mn (Mangânes), Pb (Chumbo) e Zn (Zinco) podem ser encontrados em fontes de consumo, algo perigoso, visto que esses metais são considerados elementos tóxicos aos organismos vivos e altamente poluentes e dificilmente podem ser removidos por tratamentos convencionais de água.

Um outro metal perigoso é o Arsênio (As), muito encontrado em águas subterrâneas, e seu consumo ou exposição a longo prazo pode trazer riscos à saúde humana, como câncer de pele (CHOUDHURY et al., 2018).

Muito da preocupação em relação aos metais pesados presentes em águas contaminadas está na elevada reatividade e em seu poder de bioacumulação, pois além de serem capazes de desencadear diversas reações químicas, não são metabólicos, ou seja, organismos vivos não são capazes de degradá-los, o que faz com que permaneçam em caráter cumulativo ao longo da cadeia alimentar, provocando graves doenças aos seres vivos. Embora grande parte dos metais não serem metabolizáveis, alguns deles em pequenas quantidades participam de determinadas atividades metabólicas, como o cobal- to na produção de hemácias, e o cobre, que é essencial para a síntese de hemoglobina. Quando se eleva a quantidade desses elementos no corpo, porém, eles passam a ser tóxicos, ocasionando sérios riscos à saúde (BASTOS, 2013).

Diante disso, diversas pesquisas com os nanofiltros de carbono vêm sendo desenvolvidas a fim de estabelecer uma nova tecnologia de filtragem, devido a suas diversas características, como nanocapilaridade, porosidade, extensa área superficial, entre outros.

\subsection{Remoção de produtos químicos}

A indústria de água potável vem enfrentando dificuldades no tratamento de águas subterrâneas contaminadas com produtos químicos, que em sua maioria são defensivos agrícolas utilizados de maneira incorreta, além de sofrer também com fortes concentrações de nitrato.

$\mathrm{Na}$ classe dos herbicidas, alguns se destacam quanto ao uso, como a glifosato, o paraquat, entre outros, são os mais utilizados por agricultores para o controle de pragas. Contudo, o uso incorreto dessas substâncias pode contaminar fontes de águas próximas e até mesmo alimentos, podendo ocasionar mortes devido a intoxicação. Com isso, os nanofiltros de carbono aparecem como uma excelente solução para o problema, podendo remover ou detectar esses defensivos da água e de alimentos.

Segundo Torreto (2011), os nanotubos de carbono mostram grande potencial para a remoção ou detecção de moléculas tóxicas, estejam elas em meio aquoso ou gasoso. Assim, as nanofiltros de carbono representam uma alternativa, já que pode remover muitos contaminantes, mesmo aqueles de baixas massas molares. 


\section{METODOLOGIA}

Os estudos relacionados a respeito dos nanofiltros de carbono ainda são muito escassos no Brasil, não havendo muitas pesquisas que tenham avaliado a eficiência desse nanomaterial para a remoção de contaminantes da água. Diante disso, o presente artigo surgiu da hipótese do que os nanofiltros de carbono podem oferecer e quão eficientes são para a remoção de contaminantes no processo de tratamento da água, visto que os meios convencionais de tratamento não removem todos os contaminantes presentes na água.
Sendo assim, o artigo seguiu os princípios da revisão bibliográfica sistemática, definindo critérios para seleção de trabalhos relacionados ao estudo. O levantamento bibliográfico foi realizado em cinco bases de dados bibliográficas - ELSEVIER, IEEE, ACS Publications, SciELO e Google acadêmicos, sendo selecionados inicialmente trabalhos com títulos relevantes e dentro do intervalo dos anos 2000 a 2018, em português, inglês e espanhol, sendo divididos em quatro categorias: os relacionados aos NTCs, os relacionados à remoção de contaminantes biológicos, os relacionados à remoção de metais pesados e os relacionados à remoção de produtos químicos presentes na água.

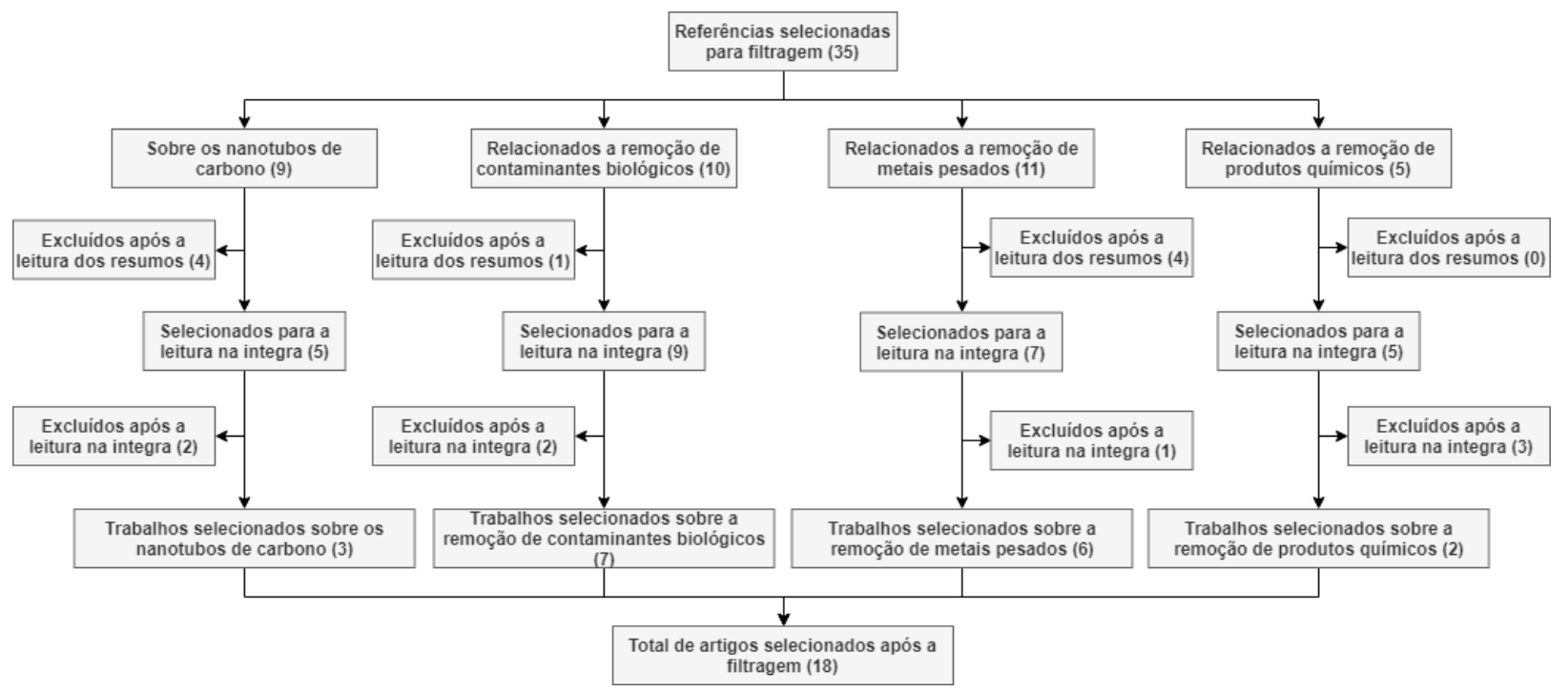

Figura 3 - Fluxograma do processo de seleção dos artigos para a pesquisa, com o número de artigos em cada etapa. Fonte: $O$ autor (2019)

Após a análise dos títulos e dos critérios supracitados, foram selecionados trinta e cinco trabalhos no total, 9 relacionados aos nanotubos de carbono, 10 relacionados à remoção de contaminantes biológicos, 11 relacionados à remoção de metais pesados e 5 relacionados à remoção de produtos químicos. Após a leitura dos resumos, foram reduzidos para 5, 9, 7 e 5 respectivamente, e com a leitura na íntegra, o número de trabalhos foi ainda mais reduzido, totalizando 18 artigos selecionados para o desenvolvimento do presente artigo. 0 processo de seleção de artigos aqui descrito pode ser observado na Fig. 3, mostrada acima, onde é apresentado o fluxograma de todo o processo de seleção.

\section{RESULTADOS E DISCUSSÕES}

Após a realização revisão bibliográfica, serão expostos os resultados obtidos para a aplicação 
dos nanofiltros de carbono para a remoção de contaminantes biológicos, metálicos e químicos presentes na água, com as principais características do processo de remoção.

\subsection{Aplicação dos nanofiltros de carbono para remoção de contaminantes biológicos}

Para a remoção de microrganismos presentes na água, a estrutura dos nanotubos de carbono se mostra extremamente eficiente, com poros que chegam a ter menos do que $1 \mathrm{~nm}$. Sendo assim, as bactérias, vírus e protozoários são adsorvidos pelos nanofiltros de carbono, enquanto as moléculas de água passam pelos poros dos nanotubos de carbono e seguem o fluxo, proporcionando a remoção de microrganismos que em muitos casos podem trazer doenças graves aos seres vivos.

Akasaka (2008) apresentou estudos com amostras de nanotubos de carbono de parede simples (SWNTs) e com nanotubos de parede múltipla (MWNTs) com diâmetros de $30 \mathrm{~nm}$ e $200 \mathrm{~nm}$, a uma concentração de $0,66 \mathrm{mg} / \mathrm{ml}$, a fim de obter resultados referentes à adesão bacteriana. $A$ quantidade residual de bactérias, em especial as Streptococcus Mutans, foram avaliadas por meio do ensaio de formação UFC (Unidade Formadora de Colônias). Com isso, foi observado que o número de bactérias livres diminuiu em todas as amostras com os NTC's, atingindo uma redução de $65 \%$ a $96 \%$ do número inicial de bactérias.

Os nanotubos de carbono de parede simples têm uma estrutura fibrosa mesoporosa, apresentando alta capacidade de sorção, caracterizando também a adsorção de bactérias aos SWNTs que mostram taxas cinéticas extremamente rápidas. Em estudos realizados por Deng (2008) e Upa- dhyayula et al. (2009), foram observadas as taxas de cinéticas de adsorção das bactérias mais comuns encontradas na água, como Bacillus subtilis, Staphylococcus aureus e Escherichia coli, em uma concentração de 107 UFC/ml. E os resultados obtidos se mostraram extremamente satisfatórios, mostrando que $95 \%$ das bactérias são adsorvidas pelos nanotubos de carbono após um intervalo de tempo entre $5 \mathrm{~min}$ e $30 \mathrm{~min}$. 0 enorme potencial apresentado pelos nanotubos de carbono, devido à rápida cinética e à alta capacidade de sorção, sugere que os filtros POU baseados em nanotubos de carbono podem ser utilizados em tempo indefinido, se não por longo tempo, na remoção de microrganismos.

\subsection{Aplicação dos nanofiltros de carbono para remoção de metais pesados}

Para remoção de metais pesados, os nanofiltros de carbono são capazes de adsorver metais pesados como Níquel, Cádmio e Chumbo através da adsorção física, aderindo à superfície dos nanofiltros, e adsorção química, correndo a ligação química entre os elementos. Sendo assim, as moléculas de água passariam pelos poros dos nanotubos de carbono, enquanto os metais se encontrariam retidos na superfície filtrante.

Bastos (2013) realizou interações com os nanotubos de carbono a fim de obter melhores resultados na adsorção dos metais como, $\mathrm{Ni}, \mathrm{Cd}$ e $\mathrm{Pb}$, utilizando-se assim, nanotubos de parede simples puro (SWNT-P) e com radicais orgânicos oxigenados, carboxila (SWNT-COOH) e hidroxila (SWNT-OH), como pode ser visto na Fig. 4. 
(a)

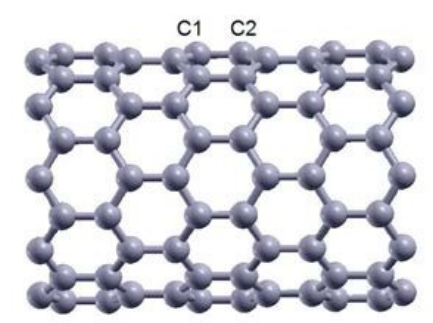

(b)

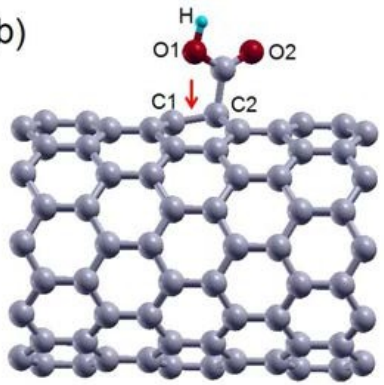

(c)

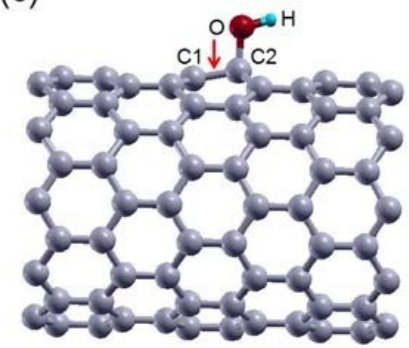

Figura 4 - Configuração estrutural dos SWNTs: (a) SWNT-P, (b) SWNT-COOH, (c) SWNT-OH. Fonte: Bastos (2013)

Em todos os casos, os nanotubos se mostraram capazes de adsorver metais como $\mathrm{Ni}, \mathrm{Cd}$ e $\mathrm{Pb}$, seja por fisissorção (caráter físico) ou quimissorção (caráter químico). Os SWNTs que mostraram os melhores resultados foram os SWNT-P, podendo funcionar como material ativo na construção de filtros para estes metais, com a vantagem de poderem ser reutilizados, pois apresentaram uma baixa energia de ligação, sendo assim o mais indicado.

Já para a remoção do Arsênio (As), Choudhury et al. (2018) apresentam resultados satisfatórios para a filtração com nanotubos de carbono de parede múltipla por meio da filtração por coluna. $\mathrm{Na}$ Fig. 5 pode-se observar um resumo dos resultados obtidos para a remoção do arsênio da água.

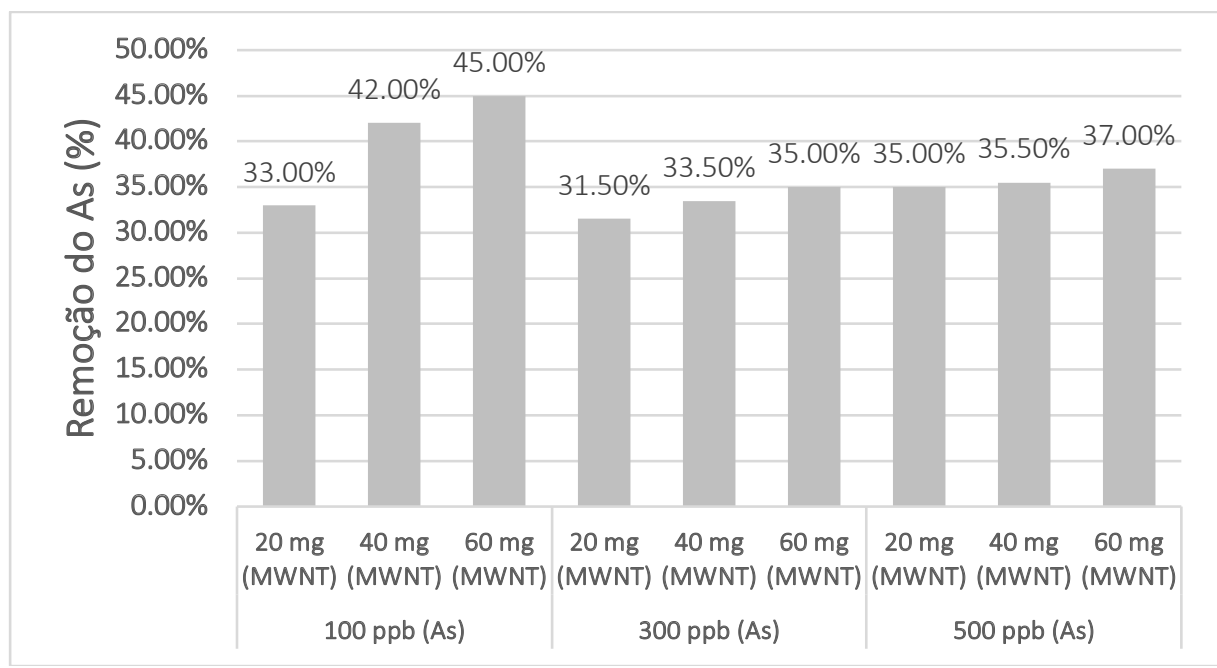

Figura 5 - Remoção do Arsênio (As), em concentrações de 100ppb, 300ppb e 500ppb, com concentrações de nanotubos de carbono de $20 \mathrm{mg}, 40 \mathrm{mg}$ e $60 \mathrm{mg}$.

Fonte: Adaptado de Choudhury et al. (2018).

Outro metal considerado perigoso é o Zinco (Zn). Segundo Lu et al. (2006), os nanotubos de carbono apresentam um grande potencial para a remoção desse elemento químico da água. Na Fig. 6 pode-se observar uma síntese dos resultados obtidos por Lu et al. (2006) para a adsorção do $\mathrm{Zn}^{2+}$ disposto em meio aquoso com os SWNTs e MWNTs purificados, com concentrações de $10 \mathrm{mg} / \mathrm{l}$ e $60 \mathrm{mg} / \mathrm{l}$ para ambos, sendo também realizada uma comparação com o carvão ativado em pó (PAC). 


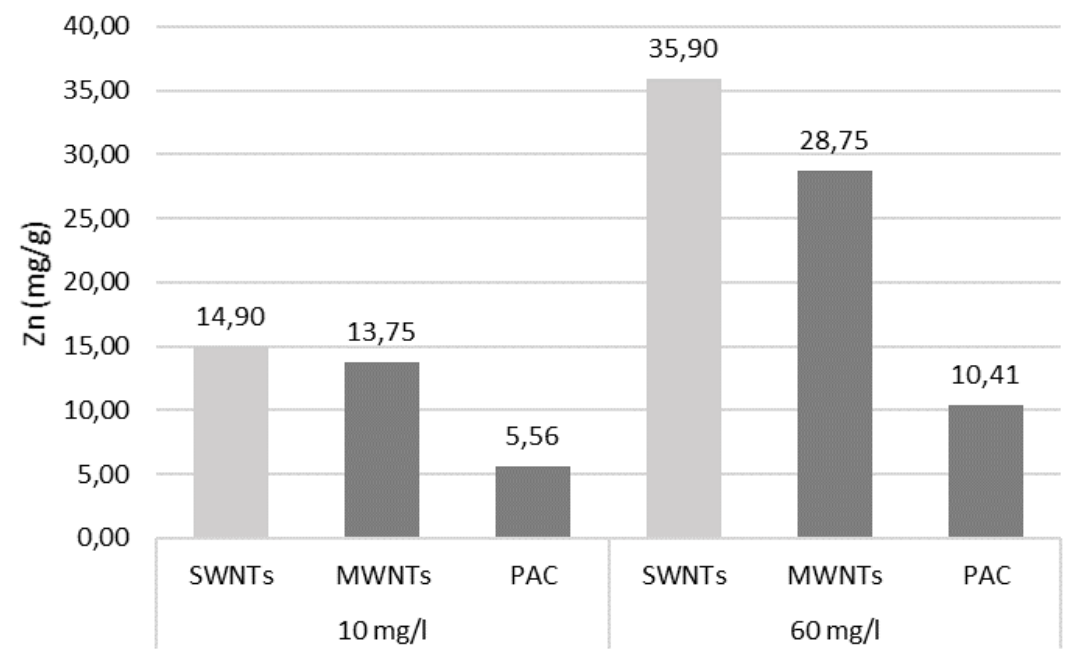

Figura 6 - Adsorção de $\mathrm{Zn}^{2+}(\mathrm{mg} / \mathrm{g})$ com SWNTs e MWNTs purificados e carvão ativo em pó (PAC) em concentrações de $10 \mathrm{mg} / \mathrm{l}$ e $60 \mathrm{mg} / \mathrm{l}$.

Fonte: Adaptado de LU et al (2006).

Ao observamos a Fig. 5, vemos que inicialmente para ambas as concentrações de CNTs, o que apresentou o melhor resultado para a adsorção do $\mathrm{Zn}^{2+}$ foram os SWNTs com $14,90 \mathrm{mg} / \mathrm{g}$ e $35,90 \mathrm{mg} / \mathrm{g}$, superando os MWNTs e o PAC, que apresentou os resultados mais baixos entre os três.

\subsection{Aplicação dos nanofiltros de carbono para remoção de produtos químicos}

Alguns resultados também podem ser levantados a respeito da remoção de produtos químicos, em geral defensivos agrícolas, que são prejudi- ciais à saúde humana e que podem ser encontrados em água destinadas ao consumo.

Em estudos realizados por Tonetto (2011), os nanotubos de carbono se apresentaram como um ótimo filtro para a remoção de produtos químicos agrícolas como glifosato e seus derivados e o paraquat. Para isso, foram realizadas iterações dos herbicidas com os nanotubos de carbono de parede simples puro (SWNT-P) e os nanotubos de carbono carboxilados (SWNT- $\mathrm{COOH}$ ), sendo dispostas configurações para as estruturas moleculares, para a análise da adsorção dos nanotubos de carbono.

Quadro 1 - Regime de adsorção dos herbicidas com os nanotubos de carbono.

\begin{tabular}{|c|c|c|c|c|c|}
\hline Tipo & Glifosato & AMPA & Metilamina & Formaldeído & Paraquat \\
\hline SWNT-P & Física & Física & Física & Física & Física \\
\hline SWNT-COOH & Física & Química & Química & Física & Física \\
\hline
\end{tabular}

Fonte: Adaptado de Tonetto (2011).

No Quadro 1, mostrado acima, são apresentados os regimes de adsorção obtidos em cada iteração realizada entre os nanotubos de carbono puro e carboxilado com os herbicidas, observando que em grande parte são de cará- ter físico, devido às baixas energias de ligação (eV). Em apenas duas situações foi observado um valor maior para a energia de ligação, caracterizando-a como adsorção química. Isso mostra que os herbicidas em questão não alteram 
as propriedades estruturais dos nanotubos de carbono, o que é de grande importância, pois permite a reutilização após a remoção das moléculas dos herbicidas.

\section{CONCLUSÃO}

A grande necessidade de inovação para os processos de tratamento de água convencional faz com que os nanofiltros de carbono se apresentem como uma das grandes soluções futuras para a descontaminação da água. Suas excelentes propriedades estruturais e químicas tornam esse material um dos mais estudados por cientistas na atualidade. Suas características proporcionam a remoção de microrganismos como bactérias, vírus e protozoários, metais pesados como, $\mathrm{Ni}, \mathrm{Cd}, \mathrm{Pb}$, As e $\mathrm{Zn}$, além de permitir a retirada de produtos químicos como, glifosato e seus derivados, paraquat e nitrato presentes em fontes de água potável.

Sendo assim, os nanofiltros de carbono se mostram como uma das grandes alternativas para a descontaminação e purificação das fontes de água potável, recurso esse que está se tornando limitado e é de extrema importante para a sobrevivência dos seres vivos.

\section{CONTRIBUIÇÃO DOS AUTORES}

Todos os autores contribuíram de forma igualitária.

\section{REFERÊNCIAS}

AKASAKA, T.; WATARI, F. Capture of Bacteria by flexible carbon nanotubes. ELSEVIER - Science of the Total Environment. Acta Biomaterialia. Volume 5, 607-612. Setembro. 2008. https://doi. org/10.1016/j.actbio.2008.08.014

BASTOS, M. Modelagem computacional de nanotubos de carbono como nanofiltros e nanosensores para controle ambiental: um estudo de primeiros princípios. 2013. Dissertação (Mestrado em Química) - Universidade Federal de Alfenas, Alfenas, Minas Gerais.
BRUGGEN, V. B., VANDECASTEELE, C. Removal of pollutants from surface water and groundwater by nanofiltration: overview of possible applications in the drinking water industry. ELSEVIER Environmental Pollution 122, 435-445, June. 2003. https://doi. org/10.1016/S0269-7491(02)00308-1

CHOUDHURY, M. S. H.; SOGA, T.; MOMINUZZAMAN, S. M. Arsenic Removal Using Multiwall Carbon Nanotubes. 10th International Conference on Electrical and Computer Engineering 20-22. Dhaka, Bangladesh. December, 2018. Anais... https://doi. org/10.1109/ICECE.2018.8636691

DENG, S.; UPADHYAYULA K.K., V.; MITCHELL C., M.; SMITH B., Geoffrey. Adsorption Equilibrium and Kinetics of Microorganisms on Single-Wall Carbon Nanotubes. IEEE Sensors Journal. Volume 8, $n^{\circ}$ 6. June. 2008. https://doi.org/10.1109/JSEN.2008.923929

ESCOBAR, I. C., HONG, S., \& RANDALL, A. A. Removal of assimilable organic carbon and biodegradable dissolved organic carbon by reverse osmosis and nanofiltration membranes. ELSEVIER - Science of the Total Environment. March, 2000. https://doi. org/10.1016/S0376-7388(00)00398-7

GUEDES, A. J. LIMA, S. F. R. SOUZA, C. L. Metais pesados em água do rio Jundiaí - Macaíba/RN. Revista de Geologia, Vol. 18, $n^{\circ} 2$, 131-142, 2005.

KANG, S.; HERZBERG, M.; RODRIGUES F. D.; ELIMELECH, M. Antibacterial Effects of carbon Nnotubes: Size Does Matter! ACS Publications, Langmuir 2008, 24, 6409-6413. https://doi. org/10.1021/la800951v

LU, C.; CHIU, H. Adsorption of Zinc (II) from water with carbono nanotubes. ELSEVIER - Science of the Total Environment. Chemical Engineering Science 61 (2006) 1138 - 1145. https:// doi.org/10.1016/j.ces.2005.08.007

MOSTAFAVIA, S.T., M., M.R., A.M. R. Preparation of nanofilter from carbon nanotubes for application in virus removal from water. ELSEVIER - Science of the Total Environment. Volume 238, Issues 1-3, March 2009, Pages 271-280. https://doi.org/10.1016/j. desal.2008.02.018

NÓBREGA, M. R. Eficiência de membranas filtrantes de nanofiltração e osmose inversa no pós-tratamento de esgoto doméstico. Trabalho de conclusão de curso - Centro de tecnologia, Universidade Federal do Rio Grande do Norte, Natal, 2016.

LIMA, Y. O. SILVA, J.A. Potencial dos nanotubos de carbono no setor da construção civil. Caderno de Graduação - Ciências exatas e tecnológicas. Centro Universitário Tiradentes - Unit. Maceió/AL. Vol.4/2017, n. 1, p. 211.

SANTANA, P. G. BARRONCAS, R. S. P. Estudos de metais pesados (Co, $\mathrm{Cu}, \mathrm{Fe}, \mathrm{Cr}, \mathrm{Ni}, \mathrm{Mn}, \mathrm{Pb}$ e Zn) na Bacia do Tarumã-Açu Manaus AM. Revista Acta Amazônica. VOL. 37, 2007: 111 - 118.

SEGOVIA, C. B. Nanofiltros - Nanotecnología para solucionar el problema del água. Revista de Informacíon, Tecnología y 
Sociedad. Universidad Mayor de San Andrés. ISSN 1997-4044. n.5 La Paz nov. 2010.

TATEOKA, M. S. S. Tratamento de água de abastecimento por nanofiltração e osmose inversa para remoção dos carbamatos: carbaril, carbofurano e metonil. Dissertação (Mestrado em Engenharia Ambiental) - Programa de Pós-graduação da Universidade Federal de Santa Catarina. Florianópolis. 2014.

TORETTO C., B. Estudo da utilização dos nanotubos de carbono na remoção e detecção de defensores agrícolas: um estudo de primeiros principios. 2011. Dissertação (Mestrado em Nanociência) - Centro Universitário Franciscano de Santa Maria, Santa Maria, Rio Grande do Sul.
UPADHYAYULA K.K., V.; DENG, S.; MITCHELL C. M.; SMITH B. G. Adsorption of Bacillus subtilis on single-walled carbon nanotube aggregates, activated carbon and NanoCeram. ELSEVIER Science of the Total Environment. Water Research. Volume 43, 148-156. Setembro. 2008. https://doi.org/10.1016/j. watres.2008.09.023

UPADHYAYULA K.K., V.; DENG, S.; MITCHELL C. M.; SMITH B. G. Application of carbon nanotubes technology for removal of contaminants in drinking water: A review. ELSEVIER - Science of the Total Environment. Volume 408, Issue 1, 1-13. Dezembro. 2009. https://doi.org/10.1016/j.scitotenv.2009.09.027 